\title{
Electromagnetic Exhaust Valve Event Optimization for Enhancing Gasoline Engine Performance
}

\author{
Xinyu Fan and Siqin Chang \\ School of Mechanical Engineering, Nanjing University of Science and Technology, 210094 Nanjing, China
}

\begin{abstract}
Variable exhaust valve events have the potential to further improve the engine power output, fuel economy and decrease the $\mathrm{NO}_{\mathrm{X}}$ emissions. Based on the moving coil electromagnetic valve train applied to engine exhaust system, effects of variable exhaust valve events are analyzed in detail and the optimization approaches are carried out. Also with the fully variable intake and exhaust valve train, different internal EGR strategies can be achieved and the contrastive analyses are carried out between combustion chamber recirculation and exhaust port recirculation strategies at same operational condition. Results show that, the optimal exhaust valve opening motion can strengthen both power performance and fuel economy at engine part loads. And two principal EGR strategies are applied in a good combination under variable engine loads. At the engine speed of $2000 \mathrm{r} / \mathrm{min}$, BMEP is about $0.3 \mathrm{MPa}$ and with $30 \% \sim 35 \%$ exhaust port recirculation rate, the BSFC and $\mathrm{NO}_{\mathrm{X}}$ emissions have decrease over $10 \%$ and $85 \%$ respectively compare with initial condition.
\end{abstract}

\section{Introduction}

Electromagnetic valve train (EMVT) in camless engine offers large potential to maximize volumetric efficiency and minimize pumping losses, so the electromagnetic valve technology can improve engine power output and fuel economy obviously [1]. Furthermore, engine exhaust system equipped with EMVT can expand the potential of variable valve train technology, because the variable exhaust valve timing can enhance the exhaust velocity and make it easier to increase engine output power or weaken the exhaust process to reduce emissions.

E. Sher et al. researched the optimization of variable valve train for maximizing performance of an unthrottled SI engine, got conclusions that the optimal EVO and IVC for minimizing BSFC occurs in a good approximation when the engine torque maximizes in the entire range of operation condition [2]. Work by Kramer et al. demonstrated that phasing the exhaust camshaft to a later EVO and EVC at part load steady-state operation reduces hydrocarbon emissions by $10 \%$ [3]. With internal exhaust gas recirculation and variable valve timing technology, authors researched the changes of $\mathrm{NO}_{\mathrm{X}}$ emissions, then optimization works were carried out to find the optimum exhaust valve event, it was concluded that the average reduction of $\mathrm{NO}_{\mathrm{X}}$ emission and $\mathrm{BSFC}$ are $71 \%$ and $6 \%$, respectively [4].

The high combustion pressure present in the combustion chamber would be a challenge to the operation safety and stability of electromagnetic exhaust valve train. Aiming at the large variations in combustion pressure, authors adopt corresponding close loop control strategies and resulted in a desirable performance through experiments [5]. For the moving coil EMVT, Figure 1 shows the prototype equipped on cylinder head and the structure is introduced in the reference [6]. It can be competent for the engine exhaust system with inverse system control algorithms [6-7]. Also the effect of gas pressure on the power consumption of exhaust valve and the approach to define the optimal opening motion at high load has been discussed; the results showed it get a better trade-off in terms of engine torque and exhaust valve power consumption [7]. While at the engine part load, the influence of gas pressure is inconspicuous, what we more concerned about is the way to reduce $\mathrm{BSFC}$ and $\mathrm{NO}_{\mathrm{X}}$ emissions. So the objective of this paper is to extend the work described in the above, the comprehensive study on the application of variable exhaust valve events for enhancing gasoline engine performance at part load would be carried out.

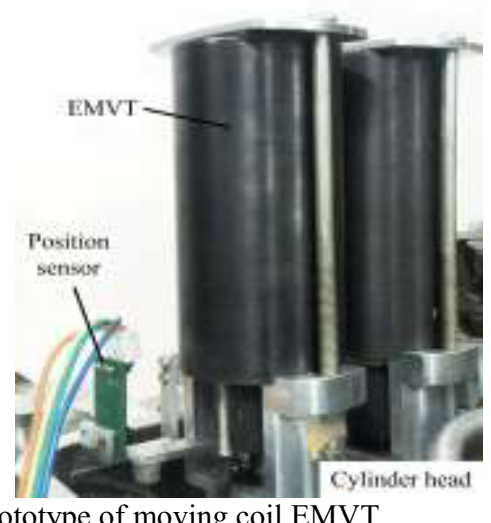

Figure 1. Prototype of moving coil EMVT. 


\section{Simulation modeling}

The study is based on an inline four-cylinder gasoline engine and main characters are shown in table 1, only port fuel injection is used to simplify the analysis.

Table 1. Four-cylinder gasoline engine data.

\begin{tabular}{|c|c|}
\hline Parameter & Value \\
\hline Displacement & $1.8 \mathrm{~L}$ \\
\hline Bore & $80 \mathrm{~mm}$ \\
\hline Stoke & $89 \mathrm{~mm}$ \\
\hline No. of valves & 16 \\
\hline Compression ratio & 10.5 \\
\hline Rated power & $95.7 \mathrm{~kW}(6000 \mathrm{r} / \mathrm{min})$ \\
\hline Rated torque & $171.3 \mathrm{~N} \cdot \mathrm{m}(4500 \mathrm{r} / \mathrm{min})$ \\
\hline
\end{tabular}

One-dimensional model of the prototype engine is carried out in AVL Boost, which can make predictions with errors less than $5 \%$ compared with test data, as shown in Figure 2. And the electromagnetic valve lift profiles are applied in the simulation model to analysis the effect of EMVT on engine performance.

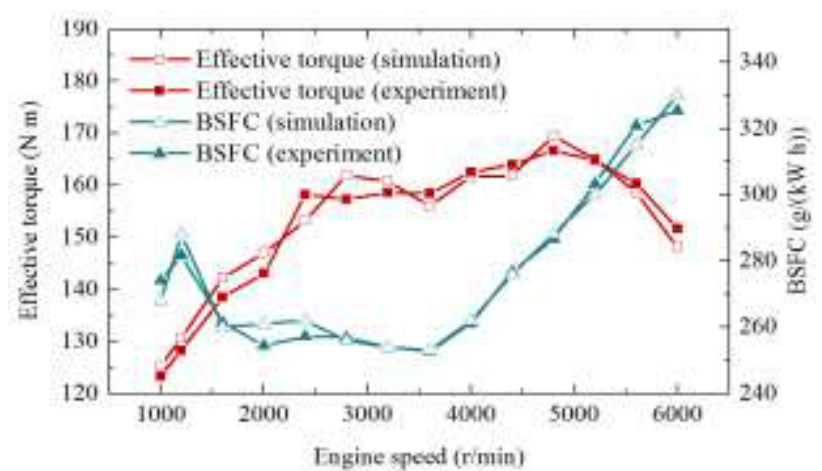

Figure 2. Comparison of simulated results and experimental results for prototype engine.

\section{Exhaust valve motion control strategy}

In the traditional camshaft engine, EVO timing is a limited compromise between power output, fuel consumption and complexity of mechanical actuation. With the electromagnetic exhaust valve train, the optimum compromise of expansion losses and exhaust work can be elaborated in every operating point through the variable exhaust valve motion. Later EVC timing and earlier IVO timing form valve overlap, which mainly determine the gas residual amount. While in the camless engine, internal EGR can be realized through the variable valve timing which is an effective way to control and minimize $\mathrm{NO}_{\mathrm{X}}$ concentration in exhaust gas. For an engine with fully variable intake and exhaust valve timing, following different procedures are possible to realize internal EGR.

Intake valve partial reopening

Exhaust valve partial reopening

Early exhaust valve closing
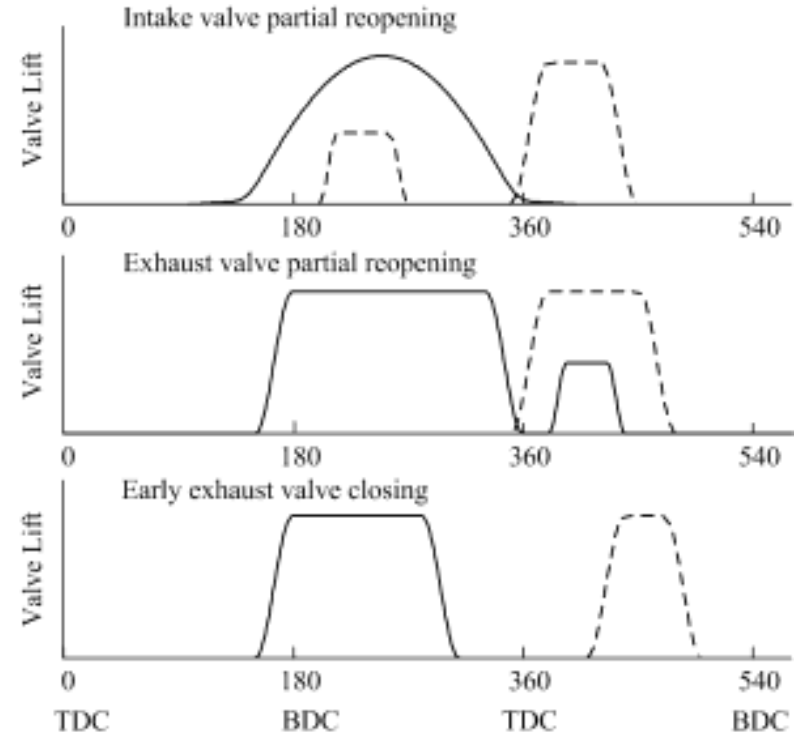

Figure 3. Internal exhaust gas recirculation strategies with variable valve events.

As shown in Figure 3, with intake valve partial reopening strategy, the intake valve opens partly during exhaust stroke. At this period, a portion of exhaust gas is pushed into intake port and would be re-pushed into combustion chamber in the next intake stroke. While the hot exhaust gas heating up fresh mixture in the intake port rapidly. This scheme to realize internal EGR has been discussed in the paper [8], it is concluded that both $\mathrm{NO}_{\mathrm{X}}$ emissions and BSFC have a great decrease. However the research in that paper was based on the engine with fully variable intake system and camshaft exhaust system, which restricted the advantage of fully variable valve train to some extent. Also the gas pressure in combustion chamber hindered the intake valve opening during exhaust stroke, which results in an increase of intake valves' energy losses.

Exhaust valve partial reopening during intake stroke forms exhaust port recirculation (EPR), part exhaust gas flows back into combustion chamber through the exhaust valve. With the optimal exhaust and intake valve timing, pumping losses could be reduced to minimum during the period of gas exchange in camless engine.

Exhaust valve closes earlier before the piston reached to top dead center, which forms negative valve overlap and then a portion of exhaust gas is remained in cylinders, this process is called combustion chamber recirculation (CCR). The trapped exhaust gas would be compressed during the final stages of exhaust stroke and re-expand until to the intake valve opened. During the intake stroke, the fresh charge and residual exhaust gas get fully mixed. Because of the recompression processes of residual exhaust gas, pumping losses of CCR strategy are higher compared with the former two strategies. Therefore, an early exhaust valve closing event often coupled to a very late intake valve opening event, which could decrease the pumping losses effectively. With this internal EGR strategy, the temperature of fresh charge is higher than other strategies. Based on the above analysis, the optimize approach and strategy about variable exhaust valve event at engine part load would be carried out below. 


\section{Results and discussion}

\subsection{Effect of exhaust valve opening events}

At the engine part load, the effect of combustion force on exhaust valve opening event is weak. So the exhaust valve opening event mainly influences the exhaust process efficiency, exhaust gas temperature and the secondary reactions of the hydrocarbon emissions in the cylinder and exhaust system. Opening the exhaust valve too early leads to higher expansion losses. Conversely, opening the exhaust valve too late leads to an increase in exhaust phase losses. Therefore, to minimize the losses in the expansion and exhaust phase, the exhaust valve opening event must be adapted to the engine load and speed.

At the engine speed of $2000 \mathrm{r} / \mathrm{min}$ and BMEP is about $0.3 \mathrm{MPa}$. The EVC timing is kept at top dead center and transition time (the time in which the valve moves from $5 \%$ to $95 \%$ of the travel) is $3.5 \mathrm{~ms}$. Also the engine load is controlled by adjusting IVC timing instead of throttle. The results are shown in Figure 4 and 5.

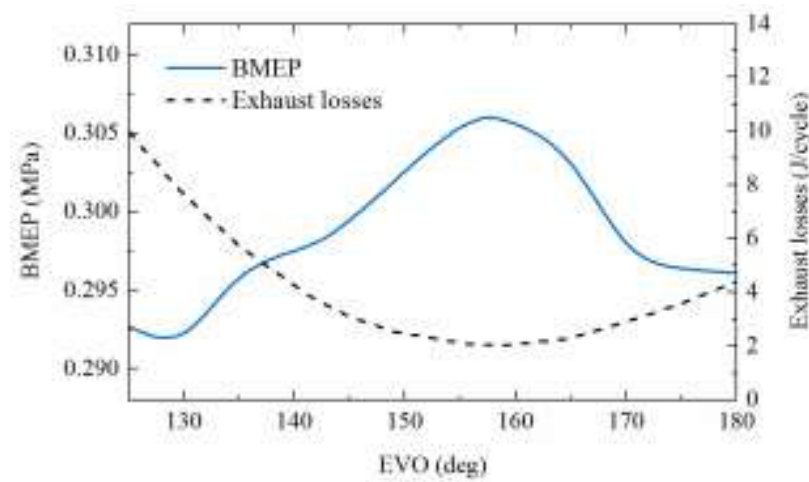

Figure 4. Effect of variable EVO timing on the BMEP and exhaust losses, at $2000 \mathrm{r} / \mathrm{min}$ and BMEP is about $0.3 \mathrm{MPa}$.

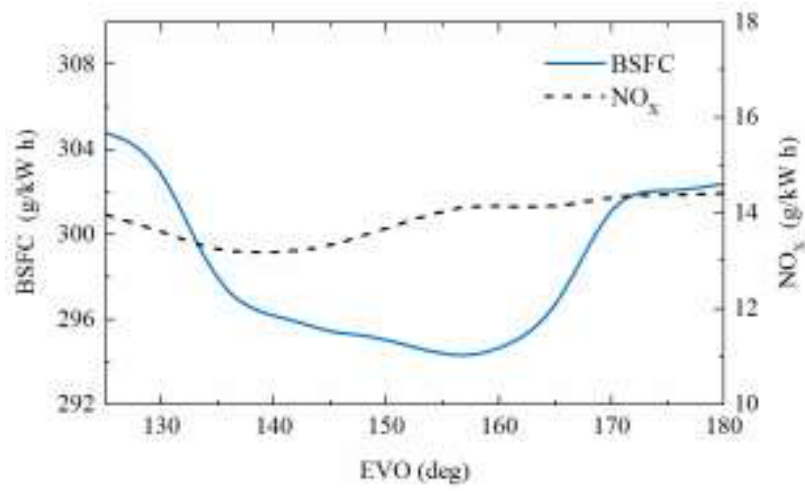

Figure 5. Effect of variable EVO timing on the BSFC and $\mathrm{NO}_{\mathrm{X}}$ emissions, at $2000 \mathrm{r} / \mathrm{min}$ and BMEP is about $0.3 \mathrm{MPa}$

For the prototype cam engine, BMEP is $0.249 \mathrm{MPa}$ with the same fresh charge per cycle at $2000 \mathrm{r} / \mathrm{min}$, the engine power has a great improvement with fully variable intake and exhaust valve train. As shown in Figure 4, the BMEP increases directly to the maximum $0.305 \mathrm{MPa}$ and then decreases with the delay of EVO timing. This is mainly caused by the changes of exhaust losses, the regions about exhaust losses achieve a minimum standard and BMEP attains maximum are mainly overlapped. Also we can see the BSFC reaches to lowest state at the same regions. So at the part load of camless engine, the optimal EVO timing for minimizing BSFC occurs in a good approximation when the engine exhaust losses reach to the lowest value, also it is usually late compared with conventional cam engine. While the $\mathrm{NO}_{\mathrm{X}}$ emissions are practically insensitive to the EVO timing.

\subsection{Effect of exhaust valve closing events and internal EGR strategies}

The CCR formed by earlier exhaust valve closing and the EPR produced by exhaust valve partial reopening would be researched here. At the engine speed of 2000r/min and BMEP is about $0.3 \mathrm{MPa}$. Only single intake valve per cylinder works for the conditions, which can improve the mixing level of fresh charge [9].

For the CCR strategy, exhaust valve opening motion remains the same and EVC timing keeps earlier ensuring larger exhaust gas stay in cylinder. While the pumping losses can be reduced to minimum coupled with later IVO timing, the choice of IVC timing is to ensure the same charge efficiency. For the EPR strategy, part exhaust gas in exhaust port flows back to cylinder with exhaust valve partial reopening. Also the result shows that changes of exhaust valve partial reopening timing in a small range has little effect on the engine performance, so a higher internal EGR rate could be carried out just through a longer opening duration time. While the choice of IVC timing is to ensure the same charge efficiency. Figure 6 (a) shows the IVO and EVC timing corresponding to variable CCR rate, figure 6 (b) shows the IVC and exhaust valve partial closing timing corresponding to variable EPR rate. Among this single/double model is applied on the exhaust valve partial reopening motion for extending the variation range of EGR rate.

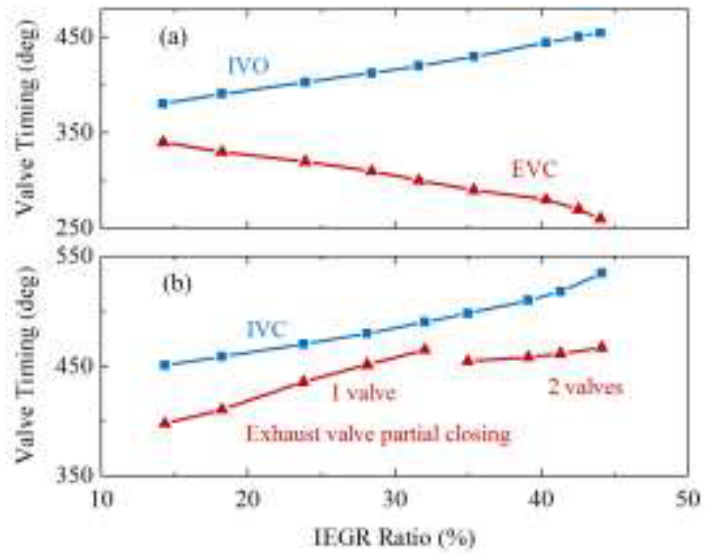

Figure 6. (a) Variable valve timing for CCR strategy. (b) Variable valve timing for EPR strategy.

Figure 7 and 8 show the thermodynamic results about two different internal EGR strategies. With the increase of internal EGR rate, BMEP increases gradually and reaches its maximum at 30\% 35\% internal EGR rate, and then dropped rapidly, also the BSFC has a small improvement but then rises sharply. The reason for this result is that the motions of intake and exhaust valve. At the part load of camless engine, the amount of fresh charge is controlled by earlier IVC timing instead of throttle, which leads to a 
small pumping loss but also decreases the temperature of intake charge. This may affect the flame propagation and heat release rate at initial combustion period. So with a higher internal EGR rate, the residual exhaust gas can heat the fresh charge and improve the combustion efficiency. While the exhaust gas with high specific heat which could decrease the peak combustion temperature in cylinder and limit the production of $\mathrm{NO}_{\mathrm{X}}$, as shown in figure 8 . With the increase of internal EGR rate further, the residuals gas rate keeps rising and results to a diluted fresh charge. Also the heating effect of exhaust gas becomes more and more obvious, which hinders the flame propagation or even results to slow-burn and partial burning. So although the $\mathrm{NO}_{\mathrm{X}}$ emissions reduce further, yet the engine power and BSFC get worsen.

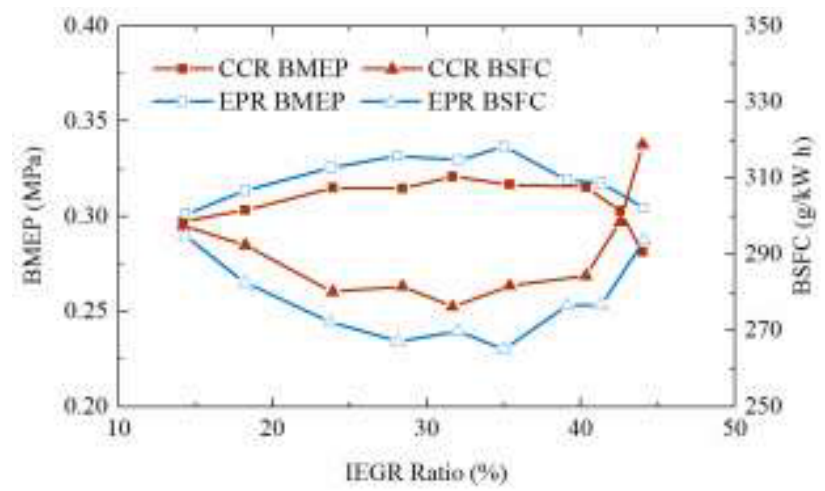

Figure 7. BMEP and BSFC with various levels of internal EGR introduction.

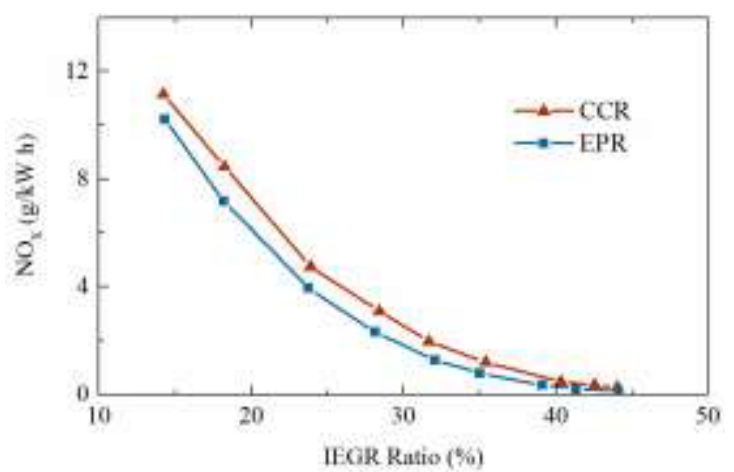

Figure 8. $\mathrm{NO}_{\mathrm{X}}$ emissions with various levels of internal EGR introduction.

Results show the difference between CCR and EPR strategies at the same engine load. Under variable levels internal EGR rate, the BMEP and BSFC for EPR strategy are superior to the CCR strategy. Which led to this phenomenon are mainly two different aspects. Firstly, the process of CCR determines it would produce larger pumping losses than EPR inevitable even though coupled with later IVO. Figure 9 shows the P-V indicated diagram of prototype engine, $18 \%$ CCR strategy and 18\% EPR strategy. Secondly, it can attribute to the effect on combustion process. As shown in Figure 10, when the piston reaches the $\mathrm{BDC}$ during the later stage of intake stroke, the fresh charge temperature of CCR is higher than EPR with a maximum difference about $40 \mathrm{~K}$. Also it can be seen that the maximum pressure rise of CCR is higher than EPR at the same EGR rate, which means a lower quality of combustion. With the increase of internal EGR tare, the maximum pressure rise reduced significantly.

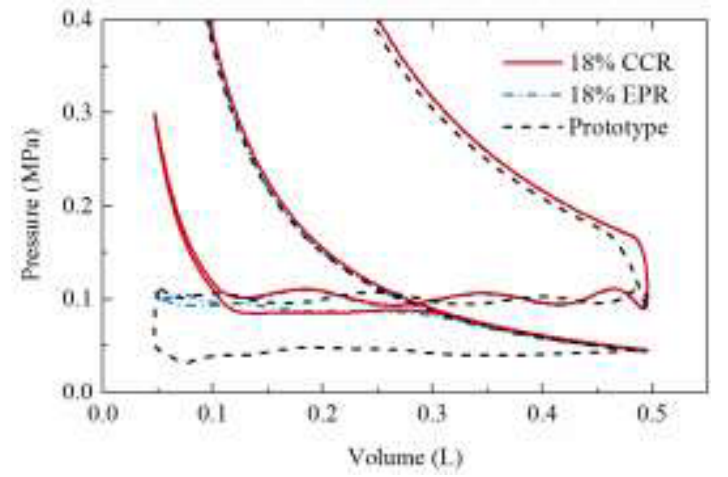

Figure 9. Pressure -Volume diagram of CCR strategy, EPR strategy and prototype.

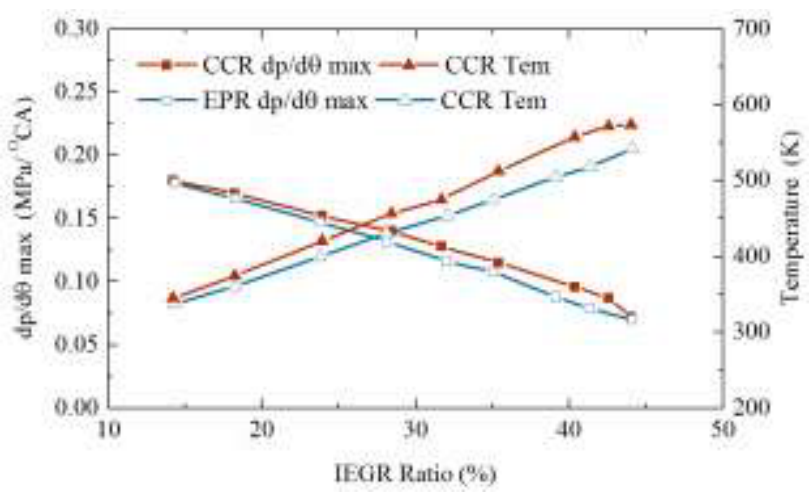

Figure 10. Maximum pressure rise and gas temperature with various levels of internal EGR introduction.

In conclusion, the maximum operational load of EPR is higher than CCR strategy. At the engine speed of $2000 \mathrm{r} / \mathrm{min}$ and BMEP is about $0.3 \mathrm{MPa}$, the optimal target is to maximize the engine power under invariable charge efficiency. Result shows with 30\% 35\% EPR rate, which get a perfect compromise between engine's fuel economy and $\mathrm{NO}_{\mathrm{X}}$ missions. In comparison with initial condition, the $\mathrm{BSFC}$ and $\mathrm{NO}_{\mathrm{X}}$ emissions have a decrease over $10 \%$ and $85 \%$ respectively.

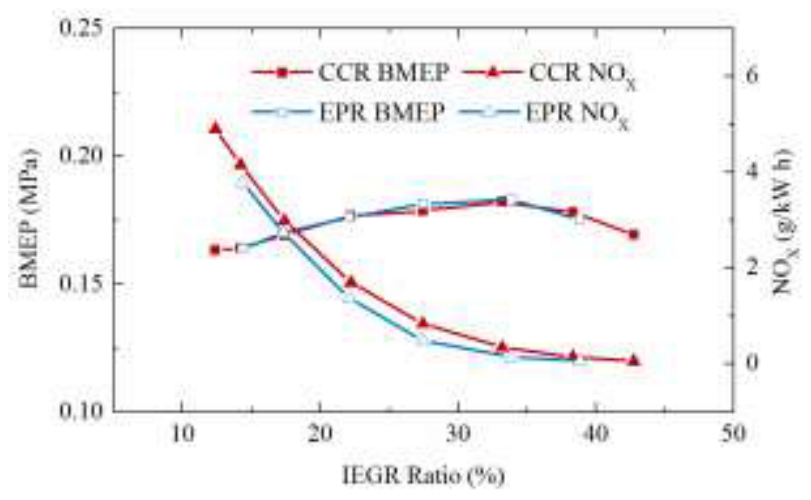

Figure 11. BMEP and $\mathrm{NO}_{\mathrm{X}}$ missions with various levels of internal EGR introduction. At $1000 \mathrm{r} / \mathrm{min}$ and BMEP is about $0.17 \mathrm{MPa}$.

While the CCR strategy is suitable to the lower engine load conditions. Because that the camless engine does not equip with throttle system, which led to a low temperature of fresh charge and combustion efficiency. And the heating effect of exhaust gas in CCR is more obvious than 
others. At the engine speed of 1000r/min and BMEP is about $0.17 \mathrm{MPa}$, the results of two different EGR strategies are shown in Figure 11. It can be inferred that the difference between two EGR strategies is not significant. But from the point of view of valve motion control, the single valve motion per cycle of CCR is easier to realize than EPR. Also a low valve frequency could decrease the power consumption and heat of EMVT.

\section{Map of control strategies with load/speed-range of the camless engine}

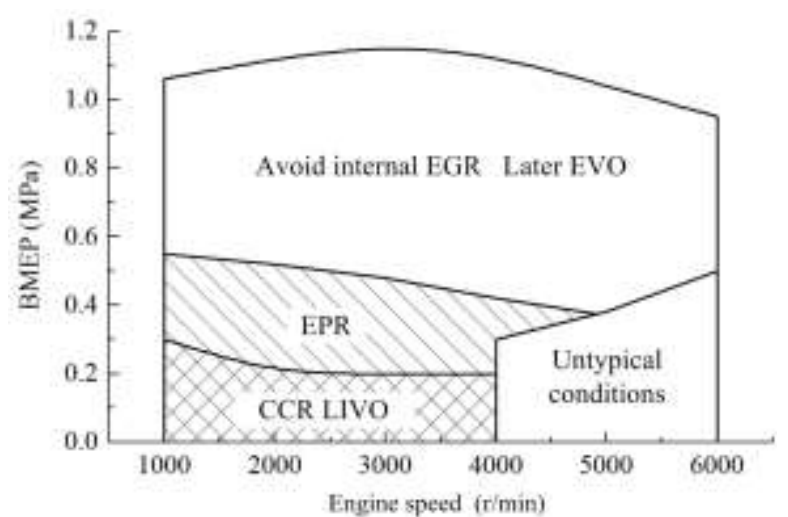

Figure 12. Map of control strategies with various operational conditions.

Based on the co-simulation models between AVL Boost and Matlab, and the genetic algorithm is used for optimization. So the map of EMVT control strategies is carried out under all operating conditions as shown in figure 12. The maximum operational region of CCR is often less than $0.2 \sim 0.3 \mathrm{MPa}$ because of the prominent heating effect of exhaust gas, it also needs to couple with later IVO to avoid high pumping losses. While the application of EPR strategy makes it possible to extend the maximum load to about 0.5 MPa BMEP. With the engine load increases further, internal EGR rate should be decrease or even avoided. Because the high intake temperature caused by internal EGR would deteriorates the volumetric efficiency and combustion quality. Also later EVO should be adopted to decrease the gas pressure.

\section{Conclusion}

Based on the application of electromagnetic intake and exhaust valve train in camless engine, this paper mainly discusses the variable exhaust valve motions for engine performance improvement. Main results are summarized as followed:

(1) At engine part load, the optimal EVO timing for minimizing BSFC occurs in a good approximation when the engine exhaust losses reach to the lowest value. It is usually later than cam engine.

(2) EPR strategy gets a higher operational region to about $0.5 \mathrm{MPa}$ BMEP compared with CCR strategy. At the engine speed of $2000 \mathrm{r} / \mathrm{min}, \mathrm{BMEP}$ is about 0.3 $\mathrm{MPa}$ and 30\% 35\% EPR, the BSFC and $\mathrm{NO}_{\mathrm{X}}$ emissions have a decrease over $10 \%$ and $85 \%$ respectively to initial condition.

(3) CCR strategy can be applied to low load conditions with the maximum operational region less than 0.2 0.3 MPa because the prominent heating effect of exhaust gas could compensate the low intake temperature. While the pumping losses can be decreased coupled to later IVO.

Through the analysis above, the optimization approaches of exhaust valve motion and internal EGR strategies are carried out, which provide a theoretical basis for the later camless engine test.

\section{References}

1. S. Y. Tong, X. J. Li, S. Liu, et al, SAE Technical Paper 2014-01-2874 (2014)

2. E. Sher, T. Bar-Kohany, Energy 27, 8, 757-775 (2002)

3. U. Kramer, P. Phlips, SAE Technical Paper 2002-01-1101 (2002)

4. A. M. Pourkhesalian, A. H. Shamekhi, F. Salimi, SAE Technical Paper 2010-01-1204 (2010)

5. J. F. Zhao, R. J. Seethaler, Mechatronics 20, 4, 433-441 (2010)

6. L. Liu, S. Q. Chang, Proc IMechE, Part D: Journal of Automobile Engineering 226, 8, 85-93 (2012)

7. X. Y. Fan, L. Liu, S. Q. Chang, et al, Int. J. Automotive Technology. (to be published)

8. B. B. Sun, S. Q. Chang, L. Liu, Automotive Engineering 36, 2, 145-150 (2014)

9. D. E. Ramajo, N. M. Nigro, J. Eng. Gas Turbines Power 132, 5, 052804 (2010) 